\title{
Reduction and Elimination of Harmonics using Power Active Harmonic Filter
}

\author{
R. Senthil kumar, R. Surya Prakash, \\ B. Yokesh Kiran, Anshuman Sahana
}

\begin{abstract}
The Three Phase 4 wire Harmonic Filter is used to mitigate harmonics which is caused by expanding utilization of present day control electronic system and mechanical assembly drives, uninterruptible power supplies, SMPS and so on. These are responsible of producing nonlinear current and accordingly stack in the system with Harmonics. The capacitance of the power capacitor frames a dangerous circuit related to the sustaining transformer. Experience demonstrates that the selffull recurrence of this circuit is commonly somewhere in the range of 250 and $500 \mathrm{~Hz}$, for example in the locale of the fifth and seventh Harmonics. Loads requiring consonant separating incorporate 6-pulse drives (AC/DC), UPS, recurrence converters. Active harmonic filters diminish your THD levels to inside IEEE/CEA limits. These channels are IGBT-based power converters. This channel infuses negative of the consonant current bringing about for all intents and purposes no symphonious bending. Phase balancing and power factor correction is also achieved. The simulation output and experimental results are found to be satisfaction because our goal is subject in mitigation of harmonics and power quality improvement.
\end{abstract}

Keywords--- Shunt Active Power Filter (SAPF), THD (Total Harmonic Distortion), PQ Theory, VSC (Voltage Source Converter), CSC (Current Source Converter).

\section{INTRODUCTION}

Power quality will demonstrate the capability of electric power to customer gadgets. In reality control quality is a similarity issue in which the types of gear associated with the network must be perfect with the lattice occasions and in the meantime the power conveyed by the lattice is additionally perfect with the supplies. All things considered in power network generally stacks does not have linear conduct at AC mains and that would absorb consonant flows from the supply. Loads, for example, electric machines, transformers, SMPS and reactors does not carry as linear loads because of immersion in attractive circuits [1].

For the most part fluctuating burdens, for example, electric sledges, spikes, sags, swell and exchanging gadgets carries on as exceedingly nonlinear burdens. Alternating current utilizing thyristors, power diodes and semiconductor switches is broadly connected to feeding controlled in electric capacity for electric burdens for example, customizable speed drives, lighting gadgets, controlled warmers, fans, attractive power supplies, chargers, SMPS, arc furnaces and so on [2].

Revised Manuscript received July 10, 2019.

R. Senthil kumar, SRM Institute of Science and Technology, Chennai, T.N, India. (e-mail: rskrren@gmail.com)

R. Surya Prakash, SRM Institute of Science and Technology, Chennai, T.N, India. (e-mail: surya005.sp@gmail.com)

B. Yokesh kiran, SRM Institute of Science and Technology, T.N, India (e-mail: yogash1095@gmail.com)

Anshuman Sahana, SRM Institute of Science and Technology, T.N, India. (e-mail: anshuman.sahana@gmail.com)
These heaps couldn't able to draw sinusoidal flows from AC supply framework and carry on nonlinear burdens [3].Especially the expanding entrance of intensity electronic based loads is making an expanding worry for symphonious bending in the alternating current supply network. Different issues identified with harmonic formation in control networks have been examined and talked about among researchers for quite a while. The issues are transformer heating, machines, capacitor banks, contortion of voltage waveform, voltage flutter, worst power factor, poor use of intensity network, low rating of intensity framework, obstruction with correspondence framework, reverberation, more neutral currents and so on. Some nonlinear burdens causes unbalancing and requires reactive power, which will create extra issues includes voltage guideline, imbalances characteristics in 3 stage voltages and so forth [4]. The voltage problematical nature will deliver negative flow of currents and produce sound, vibrations, torque throb, rotor warming and so forth.

As nonlinear loads shows diverse kind conduct and causing many type of issues. So they are arranged by their conduct and as indicated by those issues moderation strategies have been created. Regardless of causing such a large number of issues the utilization of these nonlinear loads expands day by due to ease, little size, striking vitality protection, basic control and low economy [5]. So one can't supplant these heaps without a doubt and they themselves causing power quality issue. Henceforth it is imperative to distinguish the issue and build up certain gadgets to alleviate control quality issues.

One conceivable arrangement is to put UPS between basic electrical network and the supply unit. Anyway UPS frameworks are great in ensuring their own heap yet they are significant supply framework polluters and regularly create issues for nearby loads. In this condition there is a requirement for well designed and inventive power circuits which can be set at client end to decrease consonant contortion levels and likewise repay reactive power. One imaginative idea is the APLC otherwise called AF's. It seems, by all accounts, to be an alluring, straight forward and feasible technique for lessening harmonics of voltage and current, voltage spikes, and other power quality problems. It infuses square with bramble inverse consonant there by dropping the first issue and improving force quality on associated control framework [6]. In addition the more profound intrigue in dynamic power channel is empowered by the development of quick exchanging gadgets which includes IGBT switches and MOSFET switches and

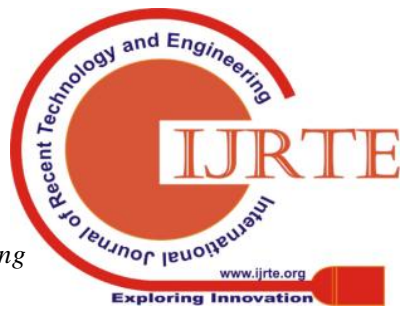


likewise by the improvement of DSP (digital signal processor), Analog to Digital converters and op-amp at sensible [7].

The three phase shunt active filter with four wire system is developed mainly for the single phase loads connected with a phase to neutral in the system. The negative sequence current is compensated by this filter. The negative sequence current will result in many power quality issues such as overheating and low efficiency of various components [8]. So this type of filter is implemented in the system to avoid these problems and to compensate reactive power.

\section{HARMONICS IN POWER SYSTEM}

\section{II.1 Loads responsible for Harmonics}

The loads absorbing non-sinusoidal flows from the supply are delegated: recognized and non-distinguished loads. Cyclo converters, electric tractions, High power diodes, heaters and electric drives are regularly portrayed as distinguished burdens, on the grounds that control utilities can undoubtedly recognized those and introduce dynamic or latent channels for harmonics remuneration or harmonic damping [7].

Be that as it may, then again a few burdens are non distinguished by the utilities, for example, a low power diode utilized as integrated in electrical applications. Numerous researchers provide extraordinary consideration regarding those loads which are unidentified [8].

\section{2 Dissemination of Harmonics}

The development and between linkage of high level of voltage framework has built the power framework all the more firm with an expanded cut off. The permissible THD level in appropriation framework is $5 \%$ as indicated by IEEE. At evenings under light burden conditions, the consonant dimension increments because of arrangement or potentially parallel symphonious reverberation between shunt capacitors and line inductors for the control factor rectification introduced on the power dispersion framework. The proposed ideology implies not just harmonic reduction in addition harmonic mitigation is powerful route for illuminating harmonic effects [9].

\section{CLASSIFICATION OF ACTIVE FILTERS}

Power electronic devices like MOSFET (Metal Oxide Semiconductor Field Effect Transistor) and IGBT harmonic injection in distribution side power systems. These are capable of fast switching and are used in many applications. Due to these switching characteristics of faster responses, researchers have proposed many active filters of different types of classification based on numbers and type of connection.

\section{III.1 Classification by Purpose/Objectives}

Basically there were two different kinds of active filters according to objectives (responsible consumers who are incorporating active filters).

- Installed by industry and independent consumers to know about harmonic loads. The major role of filter is to mitigate current harmonics at loads. (Insulated Gate Bipolar Transistor) plays major role of

- Installed in substation and in near to electric power utilities. The major role of filter is to mitigate voltage harmonics and to compensate voltage imbalance in entire power distribution systems.

\section{CLASSIFICATION BY SYSTEM CONFIGURATION}

\section{IV.1 Shunt Active Filter}

This is the most basic structure in active filters. Fig. 1 shows the shunt active filter block configuration in the stand alone system. They will draw dirtied load current from supply framework and at that point remunerated flows will be created by a few controllers and input to framework to mitigate harmonics on alternating current side of a thyristor based rectifier with direct current connect PWM based rectifier with a direct current interface capacitor or inductor.

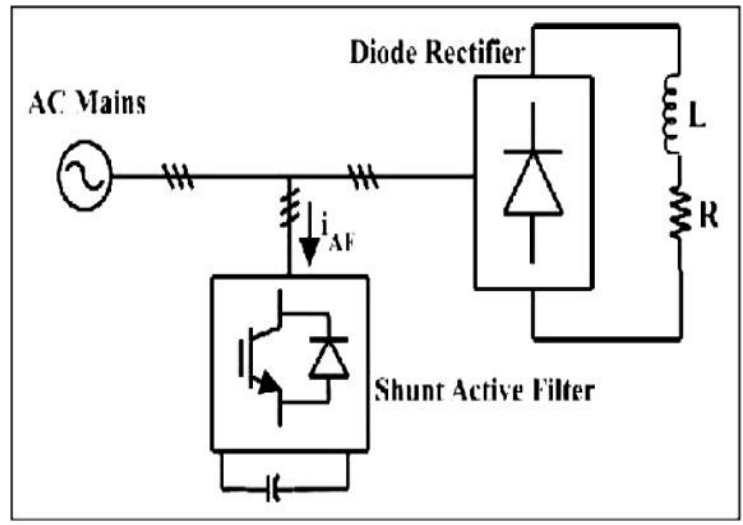

Fig. 1: Stand alone Shunt Active Filter

\section{IV.2 Series Active Filter}

These are associated in arrangement across a coordinating transformer with the goal that it should be connected to vast limit rectifier diode along with a dc capacitor. Fig. 2 shows the series APF block configuration in the stand alone system.

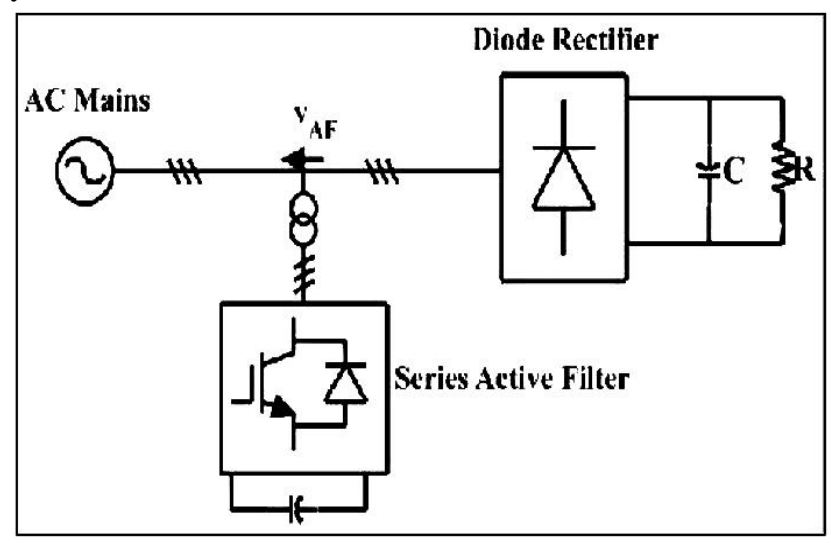

Fig. 2: Stand alone Series Active Filter

\section{IV.3 Hybrid Filters}

The shunt passive filters which consist of high pass filter with tuned LC filters. The integration of passive filter and shunt active filter has just connected for remuneration of a great extent appraised Cycloconverters.

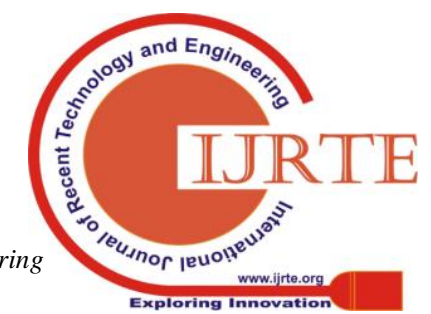


Fig. 3-5 shows the three different types of hybrid filters to minimize the capital cost and to exclude power quality issues with respect to efficiency and improvement of power factor. The integration designed in Fig. 4 and Fig. 5 is to mitigate harmonics and segregation between the voltage regulation and imbalances.

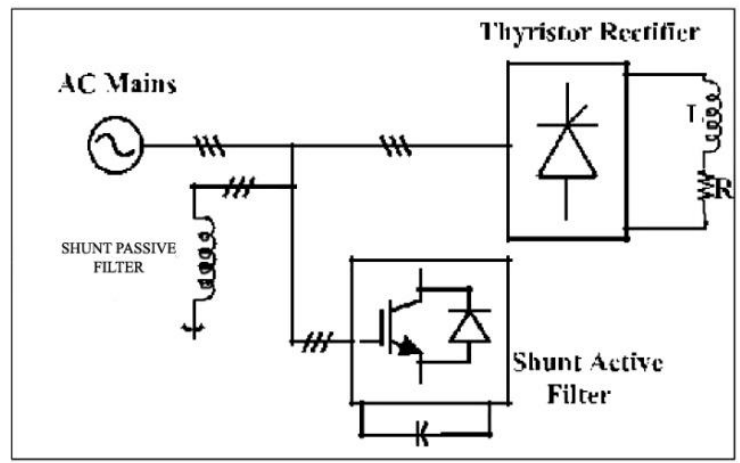

Fig. 3: Design of Active Filter and Passive filter in Shunt mode

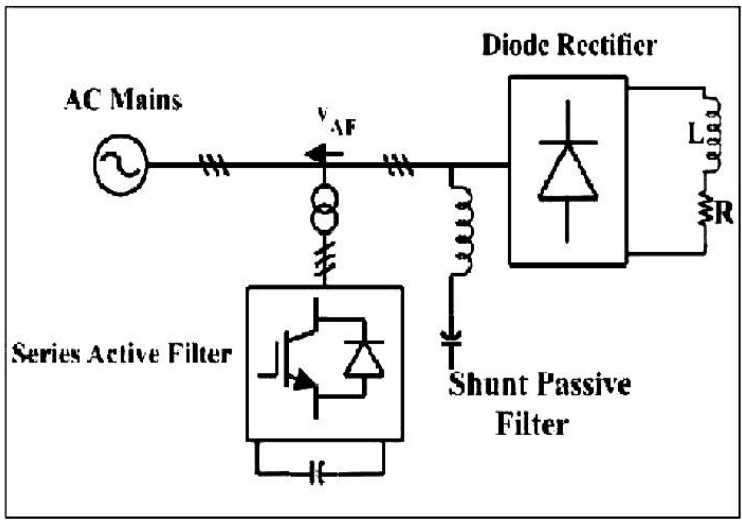

Fig. 4: Design of Passive Filter and Active Filter in shunt mode

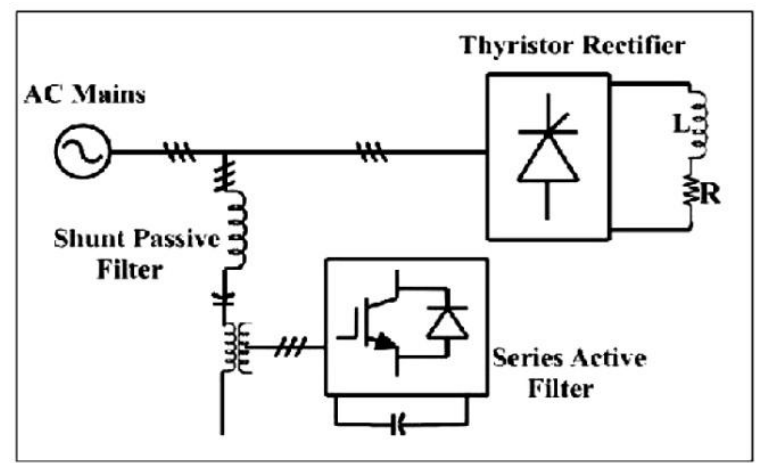

Fig. 5: Shunt Passive Filter integrated with series active filter

\section{IV.4 Three Phase Active Filters (three wire)}

This filter is integrated with the inductor in parallel to the loads producing harmonics. The inductor role is to keep the system within the rate of change of compensating current limits. Loads of inquire about going on three-wire framework in late time. Three single phase Transformers are used in SAPF. Shunt filters and series filters are used for many power quality mitigation which are used in common filter design and also in WECS.

\section{IV.5 Three Phase with Four Wire Active Filters:}

The three phase shunt active filter with four wire system is developed mainly for the single phase loads connected with a phase to neutral in the system. The negative sequence current is compensated by this filter. The negative sequence current will result in many power quality issues such as overheating and low efficiency of various components.. To mitigate this issues three phase four wire APF is specially designed. These are differentiated as four pole four-wire shunt active filter, capacitor midpoint four-wire, and threeleg4-wire SAPF. Fig. 5 represents the three phase four wire SAPF with capacitor as midpoint and Fig. 6 four pole four wire SAPF.

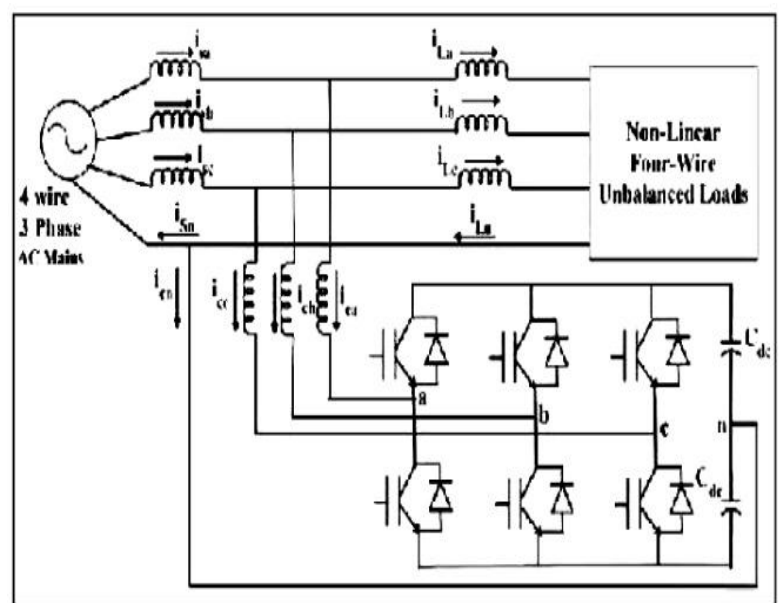

Fig. 6: Four wire SAPF with capacitor as mid-point

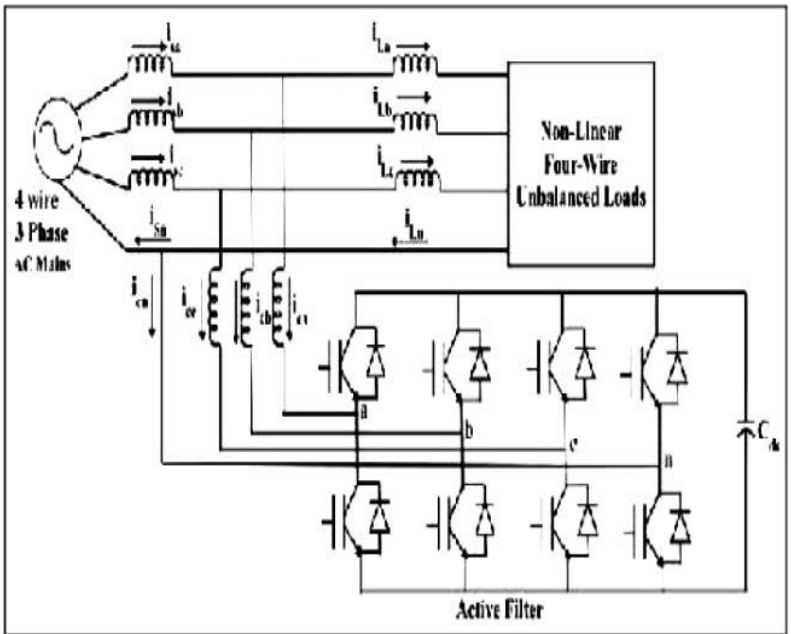

Fig. 7: Three phase SAPF with four wire and four pole

Fig. 7.represents the block diagram circuit for 3 phase 4 wire systems.

\section{THREE PHASE ACTIVE FILTERS}

Shunt Active Filter -Three Phase based on P-Q Theory:

$$
\begin{aligned}
& {\left[\begin{array}{l}
\mathrm{v} \alpha \\
\mathrm{v} \beta
\end{array}\right]=\frac{\sqrt{2}}{3}\left[\begin{array}{rrr}
1 & -\frac{1}{2} & -\frac{1}{2} \\
0 & \frac{\sqrt{3}}{2} & -\frac{\sqrt{3}}{2}
\end{array}\right]\left[\begin{array}{l}
\mathrm{va} \\
\mathrm{vb} \\
\mathrm{vc}
\end{array}\right]} \\
& {\left[\begin{array}{l}
\mathrm{i} \alpha \\
\mathrm{i} \beta
\end{array}\right]=\frac{\sqrt{2}}{3}\left[\begin{array}{rrr}
1 & -\frac{1}{2} & -\frac{1}{2} \\
0 & \frac{\sqrt{3}}{2} & -\frac{\sqrt{3}}{2}
\end{array}\right]\left[\begin{array}{l}
\mathrm{ia} \\
\mathrm{ib} \\
\mathrm{ic}
\end{array}\right]}
\end{aligned}
$$

Equations (1) and (2) are the instantaneous imaginary power and the real power with respect to $\alpha \beta$ axes can be derived as

Published By: Blue Eyes Intelligence Engineering 


$$
\left[\begin{array}{l}
p=\bar{p}+\tilde{p} \\
q=\bar{q}+\tilde{q}
\end{array}\right]=\left[\begin{array}{ll}
\mathrm{v} \alpha & \mathrm{v} \beta \\
-\mathrm{v} \beta & \mathrm{v} \alpha
\end{array}\right]\left[\begin{array}{l}
i \alpha \\
i \beta
\end{array}\right]
$$

The equations for current reference compensation in $\alpha \beta$ axes can be represented in equation (4)

$$
\left[\begin{array}{c}
i \alpha^{\prime} \\
\mathrm{i} \beta
\end{array}\right]=\frac{1}{\mathrm{v} \alpha^{2}+\mathrm{v} \beta^{2}}\left[\begin{array}{lr}
\mathrm{v} \alpha & \mathrm{v} \beta \\
\mathrm{v} \beta & -\mathrm{v} \alpha
\end{array}\right]\left[\begin{array}{l}
\tilde{p} \\
\tilde{q}
\end{array}\right]
$$

By Inverse Clarke transformation the current reference compensation are represented in equation (5)

$$
\left[\begin{array}{l}
i c a^{*} \\
i c b^{*} \\
i c c^{*}
\end{array}\right]=\frac{\sqrt{2}}{3}\left[\begin{array}{cc}
1 & 0 \\
-\frac{1}{2} & -\sqrt{3} / 2 \\
-\frac{1}{2} & -\sqrt{3} / 2
\end{array}\right]\left[\begin{array}{l}
i \alpha \\
i \beta
\end{array}\right]
$$

To achieve compensation fully, the reference current are set in every phases by inverters. The steady and balanced power is injected with the source after this process. So the components of zero sequence for voltage and current does not involve in $\mathrm{p}$ and $\mathrm{q}$ instantaneous powers.

VI. BLOCK DIAGRAM OF PROPOSED POWER ACTIVE FILTER

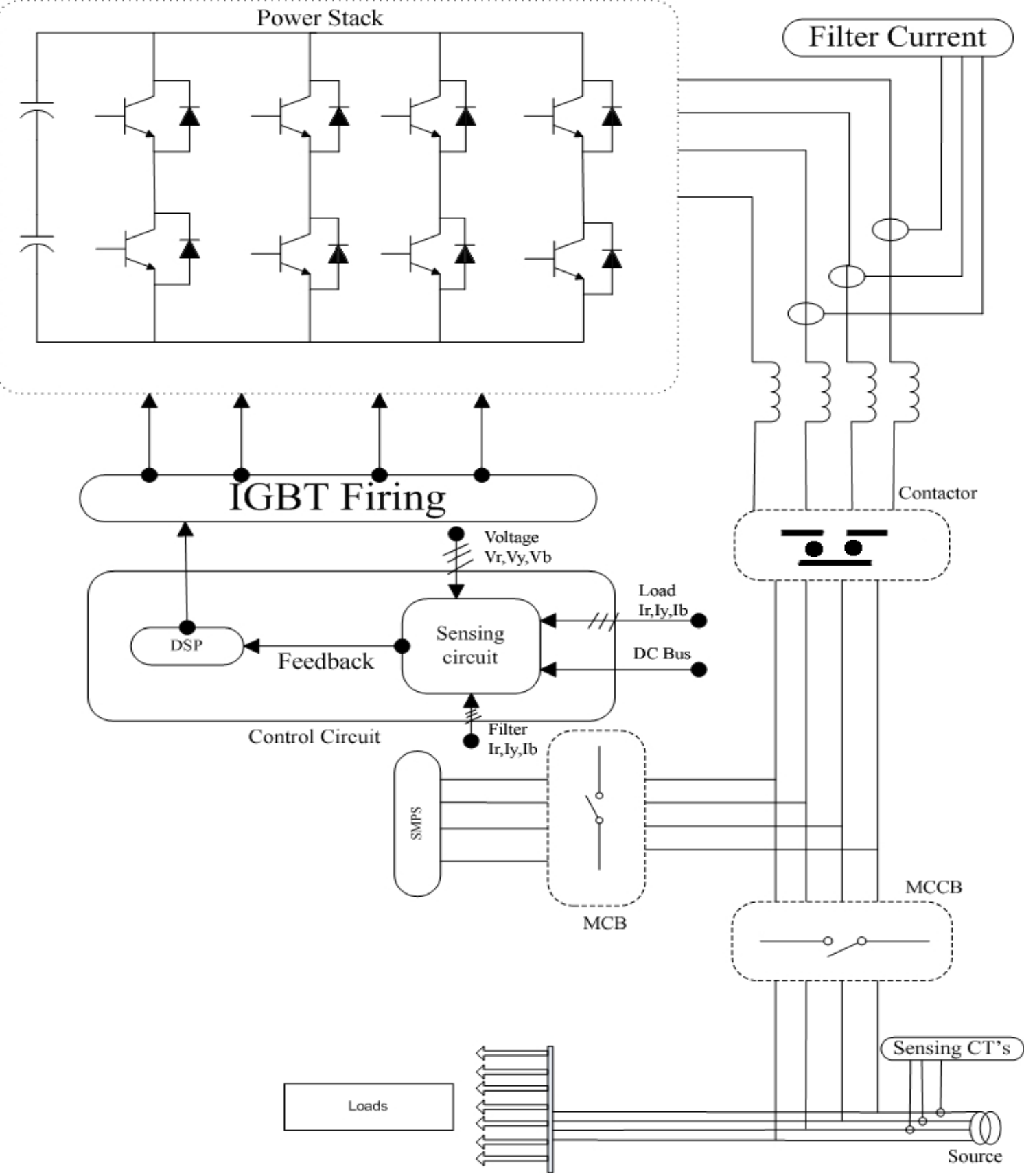

Fig. 8: The block diagram of proposed Shunt Active Power Filter

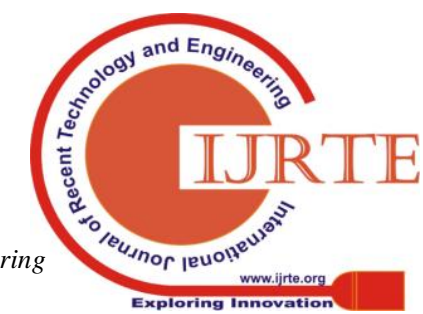


The three phase Shunt Active Filter for four wire system is used for compensation of reactive power, mitigation of Harmonics, balancing of loads, and Power factor correction. This circuit is capable of compensation of grid side supply and also for DG supply. The operation is very faster and high efficient even in the fluctuating loads. Fig. 8.represents the block diagram of proposed Three Phase Shunt Active Filter.

\section{VI.1 Power Factor Compensation}

Shunt Active Current Filters are able to correct the leading power factor conditions as well as the lagging power factor conditions. So, smooth operation is done by this type of filter. Though it provides leading and lagging power support, very accurate power factor is compensated.

\section{VI.2 Harmonic Mitigation}

These types of Filers are able to mitigate a single order of Harmonics or multiple order of Harmonics. Though it is a shunt connection, it can be easily able to connect or disconnect from a system.

\section{VI.3 Load Balancing}

In three phase system, $120^{\circ}$ phase shift and same amplitude should maintain between each phases. These filters are capable of eliminating negative sequence in current components and also correct the reactive power correction to minimize the positive sequence current and maintains unity power factor.

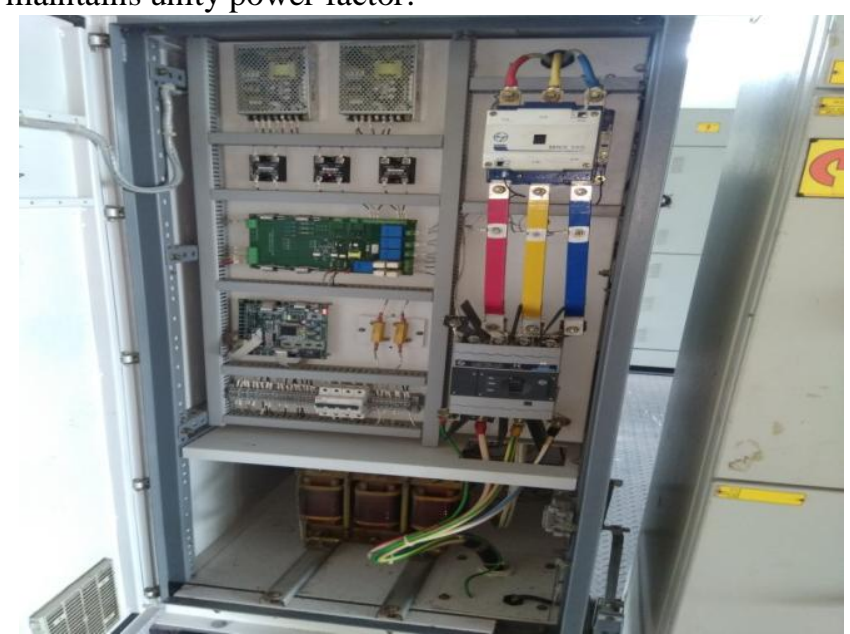

Fig. 9: Hardware of Three phase Shunt Active Filter (4wire System)

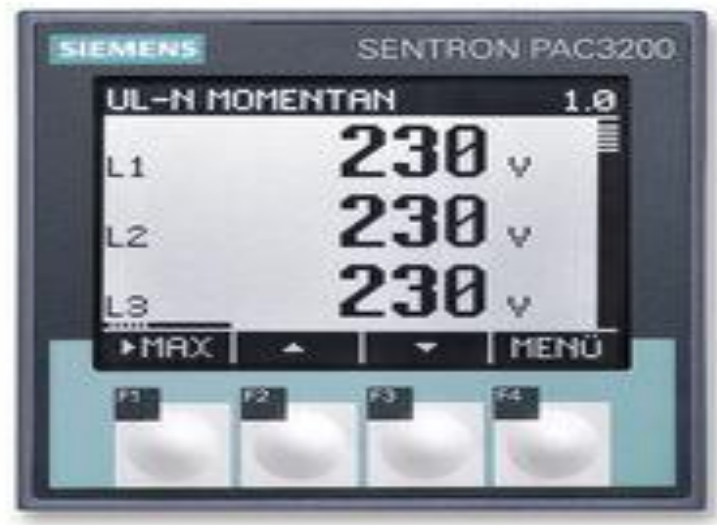

Fig. 10: Input line-voltage of the SAPF (Hardware)

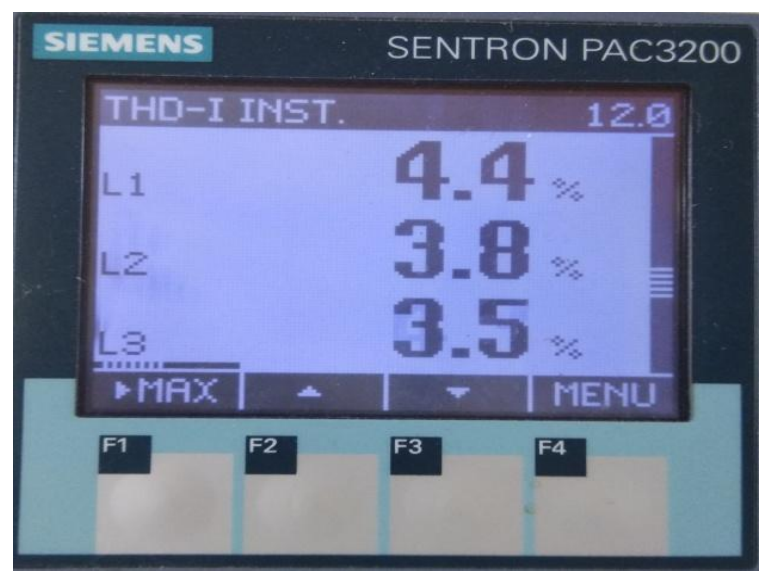

Fig. 11: THD percentage of current harmonics in the proposed system (Hardware)

Fig. 9. represents the Hardware implementation of Proposed Shunt Active Filter for Three Phase 4 wire System. Fig. 10.represents the input line to line voltage given to the filter and Fig. 11. represents the THD percentage of Current Harmonics compensated.

\section{SIMULATION OF PROPOSED POWER ACTIVE FILTER}

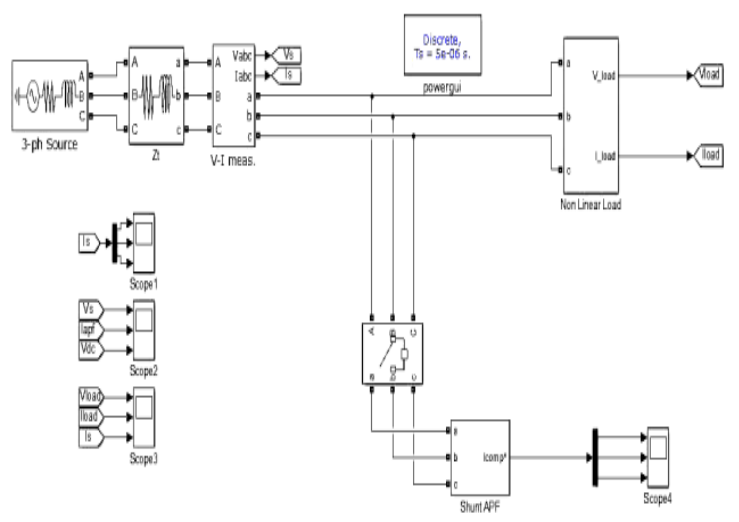

Fig. 12: Simulation circuit of proposed Shunt Active Filter for three phase system in MATLAB Simulink

In this proposed system, the voltage and current at the load are sensed in all phase and feedback to the block where control system is installed. In this system, the voltages represented as (abc) and currents are changed by conversion by the Clarke's transformation into $\alpha \beta 0$ parameters respectively. Using $\mathrm{P}-\mathrm{Q}$ theory the instantaneous reactive power and active power are calculated by these $\alpha \beta 0$ parameters. The current loop controller which is the hysteresis band controller is used to extract the reference current by selecting the power to be compensated. The gate pulses which are produced by this current controller which is fed to the inverter circuit is compared with the reference current to the actual current. So the band lies always within the limit. Two capacitors which are dc link act as the device for energy storage and perform the action of charging and discharging during a cycle of load current. Fig. 12.represents the simulation circuit of proposed Shunt Active Filter for three phase system.

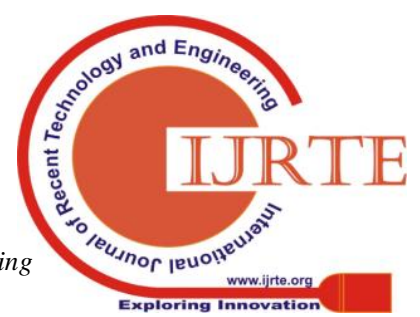




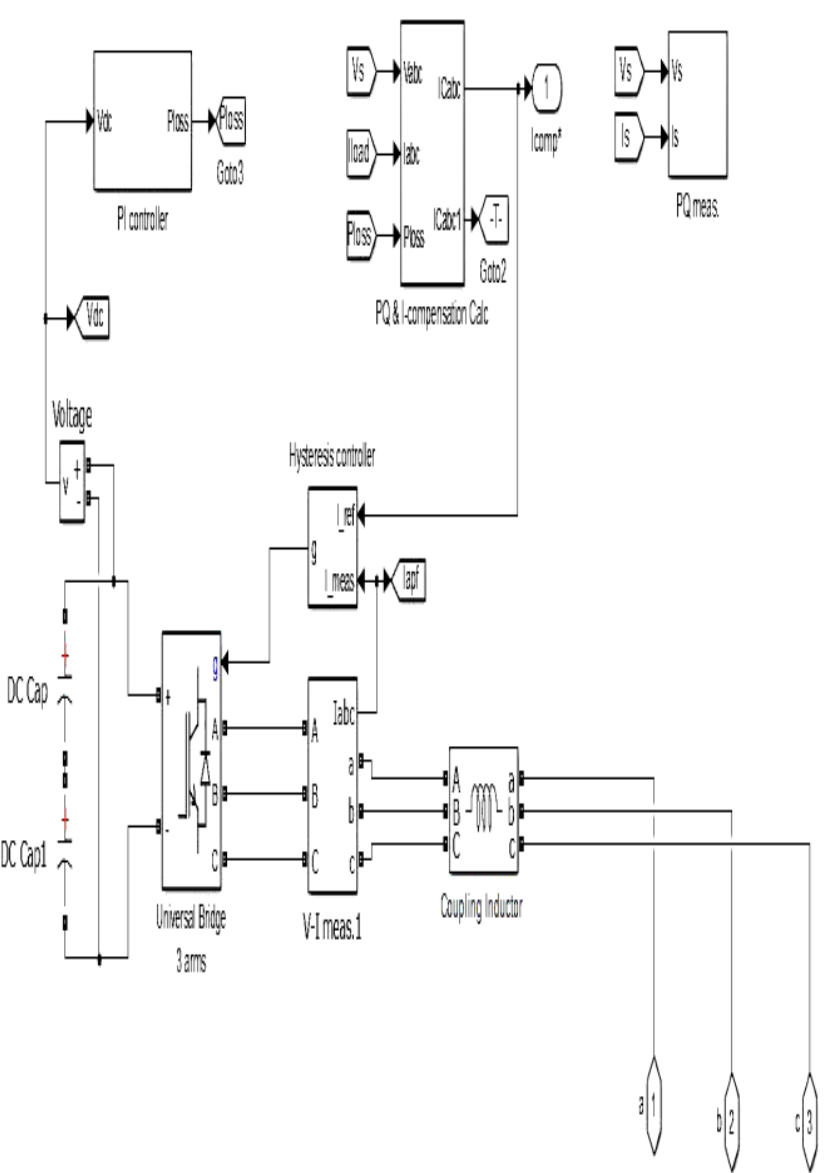

Fig. 13: IGBT and Filter circuit simulink of MATLAB

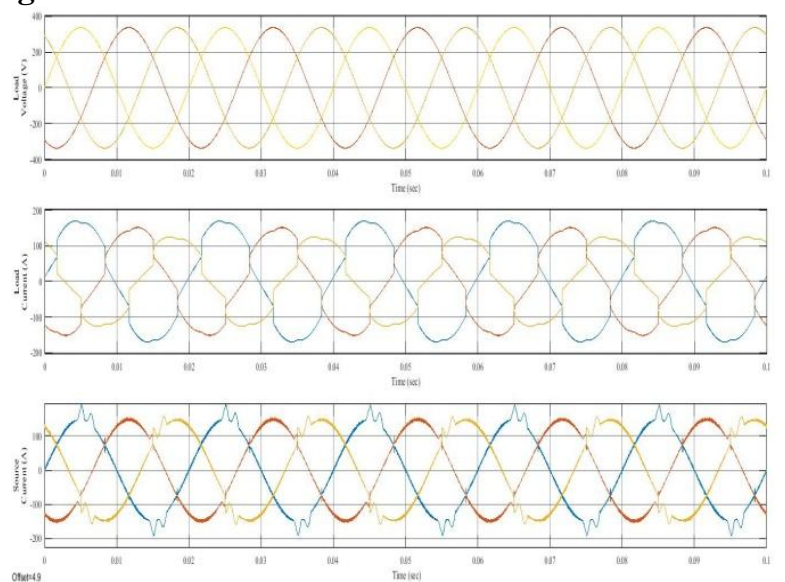

Fig. 14: Load voltage (V), Load Current (A) and Source THD Current (A) measured in MATLAB Simulink

\begin{tabular}{|c|c|c|c|c|}
\hline 0 & $\mathrm{~Hz}$ & $(D C)=$ & 0.298 & $90.0^{\circ}$ \\
\hline 16.6667 & $\mathrm{~Hz}$ & & 0.368 & $45.6^{\circ}$ \\
\hline 33.3333 & $\mathrm{~Hz}$ & & 0.238 & $36.5^{\circ}$ \\
\hline 50 & $\mathrm{~Hz}$ & (Fnd $\rangle=$ & $100 \ldots 08$ & $180.0^{\circ}$ \\
\hline 66.6667 & $\mathrm{~Hz}$ & & 0.348 & $30.5^{\circ}$ \\
\hline 83.3333 & $\mathrm{~Hz}$ & & $0.45 \%$ & $21.4^{\circ}$ \\
\hline 100 & $\mathrm{~Hz}$ & $\langle\mathrm{~h} 2\rangle=$ & 0.438 & $-23.2^{\prime}$ \\
\hline 116.667 & $\mathrm{~Hz}$ & & $0.27 \%$ & $-60.6^{\circ}$ \\
\hline 133.333 & $\mathrm{~Hz}$ & & $0.12 \%$ & $-74-7^{\circ}$ \\
\hline 150 & $\mathrm{~Hz}$ & $\langle\mathrm{~h} 3\rangle=$ & 0.118 & $-72-6^{\circ}$ \\
\hline 166.667 & $\mathrm{~Hz}$ & & $0.04 \%$ & $-81.3^{\circ}$ \\
\hline 183.333 & $\mathrm{~Hz}$ & & 0.108 & $-53.7^{\circ}$ \\
\hline 200 & $\mathrm{~Hz}$ & $\langle\mathrm{~h} 4\rangle=$ & 0.088 & $255.6^{\circ}$ \\
\hline 216.667 & $\mathrm{~Hz}$ & & 0.028 & $209.6^{\circ}$ \\
\hline 233.333 & $\mathrm{~Hz}$ & & $0.04 \%$ & $261.5^{\circ}$ \\
\hline 250 & $\mathrm{~Hz}$ & $\langle$ h5 $\rangle=$ & 0.388 & $83.0^{\circ}$ \\
\hline 266.667 & $\mathrm{~Hz}$ & & 0.018 & $-21.0^{\circ}$ \\
\hline 283.333 & $\mathrm{~Hz}$ & & 0.018 & $-86.8^{\circ}$ \\
\hline
\end{tabular}

Fig. 15: FFT Analysis of Current Harmonics A-phase using MATLAB Simulink

\begin{tabular}{|c|c|c|c|c|}
\hline THD & & $=$ & & \\
\hline 0 & $\mathrm{~Hz}$ & $\langle D C\rangle=$ & 0.468 & $270.0^{\circ}$ \\
\hline 16.6667 & $\mathrm{~Hz}$ & & $0.64 \%$ & $229.9^{\circ}$ \\
\hline 33.3333 & $\mathrm{~Hz}$ & & $0.43 \%$ & $217-1^{\circ}$ \\
\hline 50 & $\mathrm{~Hz}$ & $\langle$ Fnd $\rangle=$ & 100.008 & $60.1^{\circ}$ \\
\hline 66.6667 & $\mathrm{~Hz}$ & & 0.368 & $228-6^{\circ}$ \\
\hline 83.3333 & $\mathrm{~Hz}$ & & 0.468 & $228-6^{\circ}$ \\
\hline 100 & $\mathrm{~Hz}$ & $\langle\mathrm{~h} z\rangle=$ & $0.55 \%$ & $199.2^{\circ}$ \\
\hline 116.667 & $\mathrm{~Hz}$ & & $0.33 \%$ & $172-6^{\circ}$ \\
\hline 133.333 & $\mathrm{~Hz}$ & & 0.238 & $165.5^{\circ}$ \\
\hline 150 & $\mathrm{~Hz}$ & $\langle\mathrm{~h} 3\rangle=$ & 0.238 & $158.0^{\circ}$ \\
\hline 166.667 & $\mathrm{~Hz}$ & & $0.13 \%$ & $168.1^{\circ}$ \\
\hline 183.333 & $\mathrm{~Hz}$ & & $0.16 \%$ & $163.4^{\circ}$ \\
\hline 200 & $\mathrm{~Hz}$ & $\langle\mathrm{~h} 4\rangle=$ & $0.09 \%$ & $185.2^{\circ}$ \\
\hline 216.667 & $\mathrm{~Hz}$ & & 0.108 & $180.1^{\circ}$ \\
\hline 233.333 & $\mathrm{~Hz}$ & & $0.13 \%$ & $167.3^{\circ}$ \\
\hline 250 & $\mathrm{~Hz}$ & $\langle$ h5 $\rangle=$ & $0.43 \%$ & $202-3^{\circ}$ \\
\hline 266.667 & $\mathrm{~Hz}$ & & 0.098 & $180.5^{\circ}$ \\
\hline 283 . 333 & $\mathrm{~Hz}$ & & 0.068 & $195.5^{\circ}$ \\
\hline
\end{tabular}

Fig. 16: FFT Analysis of Current Harmonics B-phase using MATLAB Simulink

\begin{tabular}{|c|c|c|c|c|}
\hline IHD & & 0 & & \\
\hline 0 & $\mathrm{~Hz}$ & $(D C)=$ & $0.17 \%$ & $90 \ldots$ \\
\hline 16. 6667 & $\mathrm{Hz}$ & & 0.288 & $55.4=$ \\
\hline 33.3333 & $\mathrm{~Hz}$ & & 0.208 & $37-7^{=}$ \\
\hline so & $\mathrm{Hz}$ & (Fnd $)=$ & 100.008 & $-59.9^{\circ}$ \\
\hline 6ธ. -66ส7 & $\mathrm{Hz}$ & & $0.11 \%$ & $121-4=$ \\
\hline 83.3333 & $\mathrm{~Hz}$ & & $0.21 \%$ & $120.9^{\circ}$ \\
\hline 100 & $\mathrm{~Hz}$ & $(\mathrm{~h} 2)=$ & 0.378 & $71-3^{\circ}$ \\
\hline 116 - 667 & $\mathrm{~Hz}$ & & 0.278 & $45-4^{=}$ \\
\hline 133.333 & $\mathrm{~Hz}$ & & 0.208 & $15-7=$ \\
\hline 150 & $\mathrm{~Hz}$ & $(\mathrm{~h} 3)=$ & $0.18 \%$ & $4-8^{=}$ \\
\hline 16ธ. โธิ & $\mathrm{Hz}$ & & 0.128 & $5.5^{=}$ \\
\hline 183.333 & $\mathrm{~Hz}$ & & $0.10 \%$ & $24.5^{\circ}$ \\
\hline 200 & $\mathrm{~Hz}$ & $(h 4)=$ & $0.13 \%$ & $38.9^{=}$ \\
\hline 216.667 & $\mathrm{~Hz}$ & & 0.128 & $4-0^{=}$ \\
\hline 233.333 & $\mathrm{~Hz}$ & & 0.138 & $4.1^{=}$ \\
\hline 250 & $\mathrm{~Hz}$ & $\langle\mathrm{~h} 5\rangle=$ & 0.418 & $-30.9^{a}$ \\
\hline 26. -667 & $\mathrm{~Hz}$ & & $0.08 \%$ & $3.6^{=}$ \\
\hline $283-333$ & $\mathrm{~Hz}$ & & 0.068 & $28-4^{=}$ \\
\hline
\end{tabular}

Fig. 17: FFT Analysis of Current Harmonics B-phase using MATLAB Simulink

Fig. 13.represents the Filter circuit designed in MATLAB Simulink. Fig. 12.Represents the load voltage (V), Load Current (A) and Source Current (A) of the circuit. Fig. 15,16,17. represents the THD percentage of Current Harmonics observed in FFT analysis using MATLAB Simulink.

\section{EXPERIMENTAL RESULTS}

Table 1: Comparison results of Hardware and Software:

\begin{tabular}{|l|c|c|c|}
\hline \multirow{2}{*}{\multicolumn{1}{|c|}{ Results }} & \multicolumn{3}{c|}{ I THD (\%) } \\
\cline { 2 - 4 } & Phase A & Phase B & Phase C \\
\hline Hardware & 4.4 & 3.8 & 3.5 \\
\hline $\begin{array}{l}\text { Software } \\
\text { (Matlab simulink) }\end{array}$ & 4.52 & 4.55 & 4.46 \\
\hline
\end{tabular}

Table 1.represents the results measured in hardware and in Matlab Simulink Software. Both the Current THD results are similar in the mitigation of Harmonics.

\section{CONCLUSION}

As per the results from the hardware and software, this type of Shunt Active Filter is best suitable filter for minimization of Current Harmonics within the IEEE limits which is $<5 \%$. P-Q theory is the good control strategy and d$\mathrm{q}$ theory is the simplest method in calculation and in satisfactory result aspects. So our goal to achieve mitigation of Current Harmonics and to bring the Load Balancing, Unity Power Factor is successfully brought into its limits.

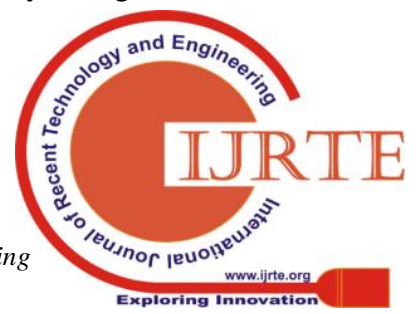


Hence we come to conclude that the Three Phase Four wire Shunt Active Filteris the best suitable method for all these aspects.

\section{REFERENCES}

1. Ajay Kumar, Harpal Tiwari, Pradeep Anjana, "Review of Active Power Filters for Improvement of Power Quality," inINROADS (International Conference IAET2016 Special Issue) Vol. 5, No. 1, Jan-June, pp-135144,2016

2. S. C. Ferreira, R. B. Gonzatti, R. R. Pereira, C. H. da Silva, L. E. B. da Silva and G. Lambert-Torres, "Finite Control Set Model Predictive Control for Dynamic Reactive Power Compensation With Hybrid Active Power Filters," in IEEE Transactions on Industrial Electronics, vol. 65, no. 3, pp. 2608-2617, March 2018.

3. Anoop H. Budhrani, Raghuvaran Naidu, Amit R Pathak, "Review on Three Phase Shunt Active Filter for Compensation of Non Linear Load Currents BasedOn pq Theory," in International Journal of Engineering Development and Research, Volume 4, Issue 4. ISSN: 2321-9939, 2016.

4. M. S. Hamad, M. I. Masoud, K. H. Ahmed and B. W. Williams, "A Shunt Active Power Filter for a MediumVoltage 12-Pulse Current Source Converter Using Open Loop Control Compensation," in IEEE Transactions on Industrial Electronics, vol. 61, no. 11, pp. 5840-5850, Nov. 2014.

5. Yu Wang, YunxiangXie, Xiang Liu,"The Influence of DC link voltage control on the performance of active power filter", in IEEE Transactions on Industrial Electronics,978-1-4799-6735-3/15, 2015

6. R. L. A. Ribeiro, T. O. A. Rocha, R. M. Sousa, E. C. dos Santos Jr., and A. M. N. Lima, "A Robust DC-Link Voltage Control Strategy to Enhance the Performance of Shunt Active Power Filters without Harmonic Detection Schemes," IEEE Transactions on Industrial Electronics, 2013

7. K. A. Puskarich, W. E. Reid, and P. S. Hamer, "Harmonic Experienceswith a Large Load-Commutated Inverter Drive," IEEE Trans. Industry Applications, vol. 37, pp. 129-136, Jan. 2001.

8. K. D. McBee and M. G. Simoes, "Evaluating the LongTerm Impact ofa Continuously Increasing Harmonic Demand on Feeder-Level Voltage Distortion," IEEE Trans. Industry Applications, vol. 50, pp. 21422149,May 2014.

9. D. Salles, J. Chen, W. Xu, W. Freitas, and H. E. Mazin, "Assessing the Collective Harmonic Impact of Modern Residential Loads-Part I:Methodology," IEEE Trans. Power Delivery, vol. 27, pp. 1937-1946,Aug. 2012.

10. J. Chen, R. Torquato, D. Salles, and W. Xu, "Method to Assess the Power-Quality Impact of Plug-in Electric Vehicles," IEEE Trans. Power Delivery, vol. 29, pp. 958965, Mar. 2014

11. A. Bhattacharya, C. Chakraborty, and S. Bhattacharya, "Shunt Compensation Reviewing Traditional Methods of Reference Current Generation," IEEE Industrial Electronics Magazine, MIE'09, vol. 3,2009, pp. 38-49.

12. H. Akagi, "New Trends in Active Filters for Power Conditioning," IEEE Trans. on Industry Applications, vol. 32, 1996, pp.1312-1322.

13. Wei Hsiang Ko, JyhCherngGu, "Impact of shunt active harmonic filter on harmonic current distortion of voltage source inverter fed drives", in IEEE Trans. on Industry Applications, 978-1-4799-8374-0/15, 2015.

14. M.T. Haque and T. Ise, "Implementation of Single Phase p-q Theory," Power Conversion Conference, PCC'02, vol. 2, 2002,pp. 761-765.
15. H. Sasaki and T. Machida, "A new method to eliminate ac harmonic currents by magnetic compensationconsideration on basic design" IEEE Trans. Power Appl. Syst. 90 (5), 2009 (1971).

16. J. Barros and E. Perez, "An adaptive method for determining the reference compensating current in single-phase shunt active power filters," in IEEE Transactions on Power Delivery, vol. 18, no. 4, pp. 15781580, Oct. 2003.

17. B. Singh, K. Al-Haddad, and A. Chandra, "A Review of Active Filter for Power Quality Improvement," inIEEE Trans. On Industrial Electronics, vol. 46, 1999, pp. 960971.

18. K. Zhou, Y. Yang, F. Blaabjerg, and D. Wang, "Optimal Selective Harmonic Control for Power Harmonics Mitigation," IEEE Trans. Industrial Electronics, vol. 62 pp. 1220-1230, Jan. 2015.

19. Q. Liu, Y. Deng, and X.He, "Boost-type Inverter-less Shunt Active Power Filter for VAR and Harmonic Compensation," IET Power Electronics, vol. 6, pp. 535542, Jun. 2013.

20. S. K. Khadem, M. Basu, and M. F. Conlon, "Harmonic PowerCompensation Capacity of Shunt Active Power Filter and itsRelationship with Design Parameters," IET Power Electronics, vol. 7,pp. 418-430, Feb. 2014.

21. S. Dineshkumar and N. Senthilnathan, "Three Phase Shunt ActiveFilter Interfacing Renewable Energy Source with Power Grid," in Proc. 2014 Communication Systems and Network Technologies Conf., pp.10261031.

22. T. Hruby, S. Kocman, and P. Pecinka, "Using Active Filter for Harmonic mitigation in Power Grid of Industry Plant," in Proc. 2015International Scientific Conf. on Electric Power Engineering, pp. 301-306.

23. G. A. Conway and K. I. Jones, "Harmonic Currents Produced by Variable Speed Drives with Uncontrolled Rectifier Inputs," in Proc.1993 IEE Colloquium on Three Phase LV Industrial Supplies: Harmonic Pollution and Recent Developments in Remedies, pp. 4/1-4/5. 